\title{
Total temporomandibular joint prosthesis as a surgical option for severe mouth opening restriction. A case report of a bilateral intervention
}

\section{Protesi dell'articolazione temporo-mandibolare come opzione chirurgica per il trattamento dell'anchilosi: caso clinico}

\author{
L. Guarda-Nardini ${ }^{1}$, D. Manfredini ${ }^{1}$, S. Berrone ${ }^{2}$, G. Ferronato ${ }^{1}$ \\ ${ }^{1}$ TMD Clinic, Department of Maxillofacial Surgery, University of Padova, Italy; \\ ${ }^{2}$ Department of Maxillofacial Surgery, University of Torino, Italy
}

\begin{abstract}
RIASSUNTO
Numerosi studi della letteratura hanno descritto differenti approcci conservativi ai disordini dell'articolazione temporomandibolare (ATM). Tuttavia, in una minoranza di casi nei quali i tradizionali trattamenti reversibili non si rivelano efficaci è necessario un approccio chirurgico all'ATM. Negli anni recenti, le protesi dell'articolazione temporomandibolare si sono rivelate una valida opzione riabilitativa in presenza di articolazioni severamente danneggiate o mutilate, come nel caso di complesse patologie infiammatorie-degenerative, o di precedenti fallimenti chirurgici. Il presente lavoro è un report clinico di un intervento bilaterale di protesizzazione dell'ATM in una paziente che lamentava una severa limitazione dei movimenti mandibolari e dolore in area temporomandibolare. Inoltre, è stata presentata una breve discussione delle potenziali indicazioni per una protesi dell'ATM, insieme alla descrizione dell'intervento chirurgico.
\end{abstract}

Reumatismo, 2007; 59(4):322-327

\section{INTRODUCTION}

T emporomandibular disorders (TMD) are a heterogeneous group of pathologies affecting the temporomandibular joint (TMJ) and/or the masticator muscles, characterized by a molteplicity of signs and symptoms, the most common of which are pain localized in the preauricular area and/or in the masticatory muscles; jaw motion abnormalities; articular sounds, such as click and/or crepitus, during mandibular movements (1). A specific etiolpathogenesis is detectable in a minority of cases, since the occurrence of TMD symptoms is often

Indirizzo per la corrispondenza:

Dott. Luca Guarda-Nardini

Department of Maxillofacial Surgery

University of Padova

Via Giustiniani, 2 - 35121 Padova, Italy

E-mail: luca.guarda@unipd.it reconductable to a multifactorial etiopathogenetic pathway (2-4). Epidemiological data show a female predominance in both general and patients' populations, and an age of onset ranging between 20 and 40 years for the most common forms (5-10).

The complex etiopathogenesis and the variability of symptoms complicates the adoption of standardized diagnostic and therapeutic approaches, as suggested by the number of treatment modalities that have been proposed, such as occlusal splints (11, 12), physiotherapy (13), behavioral and physical treatments (14), drugs (15-18), and surgery (19-24). A surgical approach to the disorders of the temporomandibular joint is reserved to a minority of cases not respondant to traditional and conservative therapies. In particular, a total temporomandibular joint replacement with alloplastic prosthesis have been introduced as a treatment option in recent years, and preliminary literature data are supportive of its efficacy (24-28). The available studies suggest 
that the main indication for a total joint replacement is the presence of a severely damaged or mutilated joint, mainly resulting from severe joint diseases or failure of previous surgeries. Also, a prosthetic TMJ replacement has been proposed in patients affected by complex inflammatory-degenerative diseases, as in the case of severe rheumatologic conditions involving the temporomandibular joint.

Considering these premises, the present manuscript is intended to present a clinical report of a bilateral temporomandibular joint replacement intervention, along with a brief discussion of TMJ prosthesis indications and description of the surgical procedure.

\section{CASE REPORT}

A 36 years-old woman (L.S.) was referred to the Department of Maxillofacial Surgery of the University of Padua, Italy, for the treatment of a severe mouth opening restriction and bilateral pain in the temporomandibular joint area.

The patient had a history of pain in the temporomandibular joint area and underwent three previous TMJ surgeries (an intervention of bilateral disk repositioning and two surgeries for condylar bone remodelling). At the time of the first assessment at our Department, the patient was not able to open her mouth (maximum mouth opening was less than five millimeters) and has been assuming oppioid analgesics for one year (Fig. 1).

3-D computerized tomography showed a bilateral degenerative osteoarthrosis with ankylosis of the temporomandibular joints, and the patient was scheluded for a bilateral intervention for total TMJ replacement.

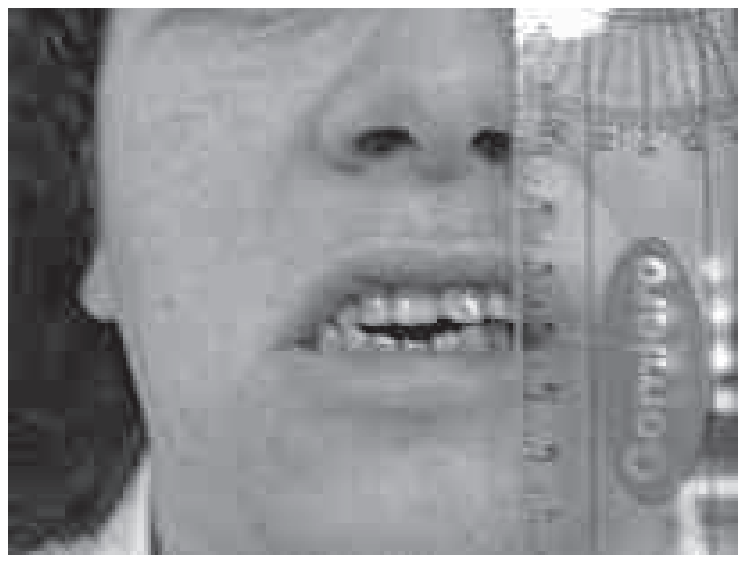

Figure 1 - Pre-operatory mouth opening.

\section{PROSTHESIS DESCRIPTION AND SURGICAL TECHNIQUE}

The total temporomandibular joint replacement system is a "ball and socket" type prosthetic joint similar to a hip implant. At present, three prosthetic system are available (TMJ Concepts ${ }^{\circledR}$; TMJ Implants $\rangle$; Biomet/Lorenz $\left.{ }^{\circledR}\right)$, and each of them is made up of three components (28):

- the condylar (or mandibular) implant, made of metal Cobalt-Chrome-Molybdenum (Co-Cr-Mo) alloy or Titanium alloy. In both cases the implants have a roughened titanium porous coating on the implant surface that contacts bone. Co-CrMo alloy contains nickel;

- the fossa implant, made of a hard, plastic polyethylene. The fossa is made of melded polyethylene that has shown excellent wear resistance during mechanical testing;

- the screws, made of titanium alloy and used to attach both the condylar and the fossa implants to bone.

In the case under description, a Lorenz total TMJ prosthesis was inserted (Biomet/Lorenz), Warsaw, IN, USA) (29).

The material selection and design parameters for this joint were based on the state-of-the-art materials currently used in the orthopaedic field to minimize risks for breakdown and ruptures (29).

The mandibular component is manufactured from Cobalt-Chrome alloy with a roughened titanium plasma coating on the host bone side of the ramus plate. The ramus of the mandibular component is made in different lenghts and, once chosen the most suitable to the patient's ramus, it is fixated to the mandibular ramus bone with self-retaining, crossdrive $2.7 \mathrm{~mm}$ self-tapping bone screws made of titanium alloy.

The fossa component is manufactured from a specific grade of ultra-high molecular weight polyethylene, which is specifically produced for articulating orthopedic designs

The surgical approach consisted of a twofold intervention phases: the removal of the ankylosis and the positioning of the temporomandibular joint prosthesis.

Both a preauricular access to the temporomandibular joint and temporal bone and a posteroinferior submandibular incision for gaining access to the mandibular ramus were requested (29).

Once the removal of the ankylosis and the heterotopic bone and scar tissue was achieved, remodelling of the glenoid fossa and a partial excission of 


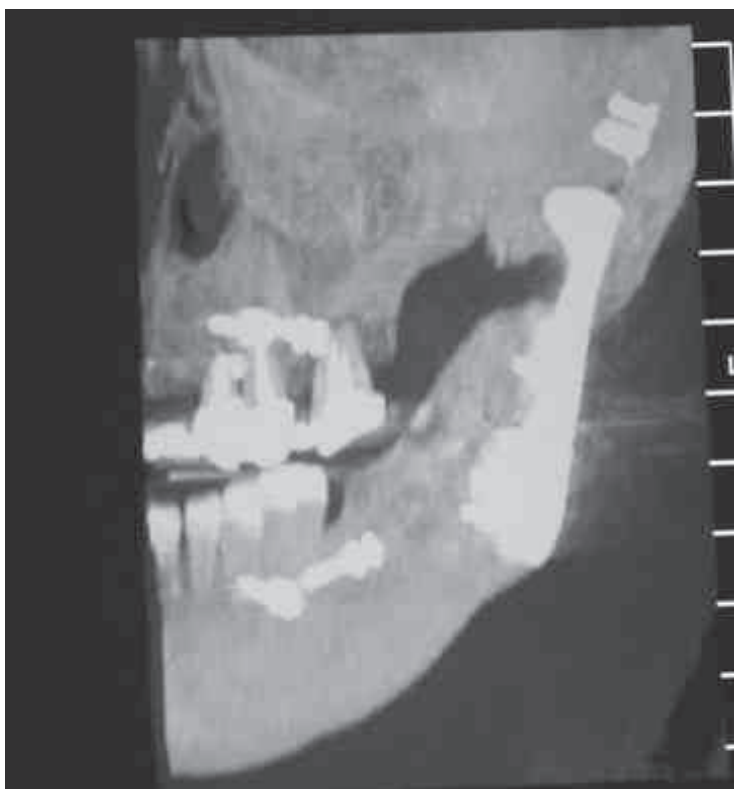

Figure 2 - Left total temporomandibular joint prosthesis.

the coronoyd process were performed to fit the fossa component of the prosthesis.

Once the fossa components of both sides were placed and fixated, the patient was placed in the post-operatory intermaxillary relationship, which was secured with wire fixation. Condylectomy was then performed and the mandibular component of the prosthesis was placed and fixated.

The intermaxillary fixation was then removed and the patient's mandible was manipulated to ensure that no obstructions to joint movement or improp-

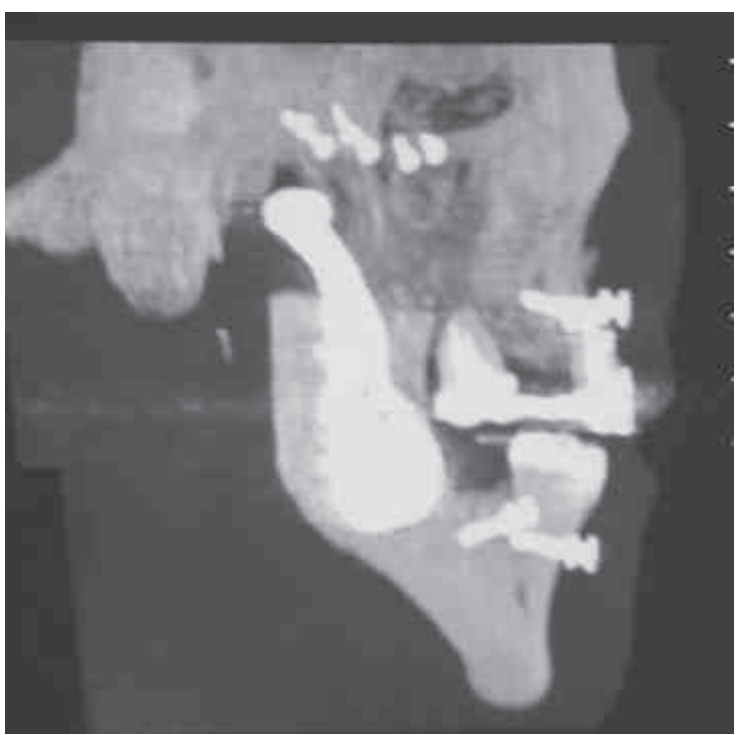

Figure 3 - Right total temporomandibular joint prosthesis.

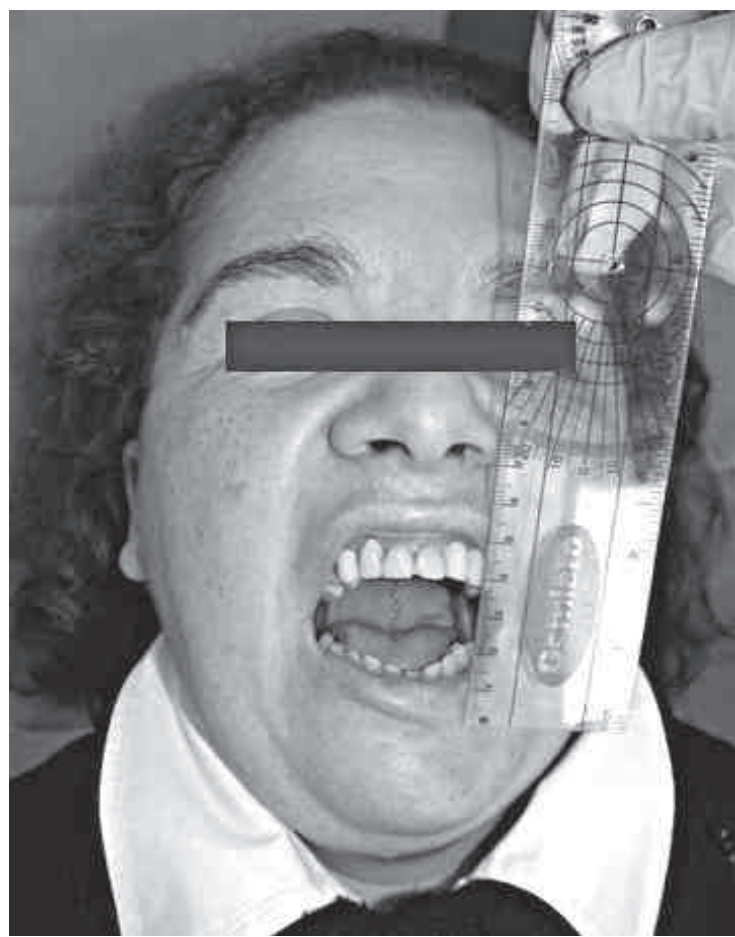

Figure 4 - Post-operatory mouth opening. One-year follow-up.

er fitting between the two prosthetic components were present. Only after verifying the correct functioning and freedom of movement of the implants, the patient was then sutured and control X-rays were executed (Fig. 2, 3).

In the case under description, the post-operative course was uneventful, and only pain killer drugs and antibiotics were prescribed. The day after surgery, a post-operatory mouth opening of $21 \mathrm{~mm}$ was recorded, with no motor deficit on either side of the face. A vigorous physiotherapy was started one week before surgery, and follow-up assessments were scheduled at one week, one month, three month, six months and one year. At the one year appointment, a maximum mouth opening of $38 \mathrm{~mm}$ was recorded (Fig. 4).

\section{DISCUSSION AND CONCLUSIONS}

Several surgical options have been described for removing temporomandibular joint ankylosis, ranging from the pioneering gap arthroplasty to the currently adopted interpositional arthroplasty, which provided the insertion of a biological (temporalis fascia, temporal muscle flap) or non-biological material (acrylic, silastic) within the bone structures (30-34). 
Similarly, a number of surgical options exists for trying to restore jaw function in severely damaged joints (19).

In both cases, the surgical failure rate is high and increase with the presence of risk factors such as a history of previous unsuccessful surgeries, and a total temporomandibular joint replacement should be considered (24). According to the currently availbale evidence, a total temporomandibular joint replacement has to be preferred with respect to a partial one, since the former allows avoiding excessive stress and wear of the articular bone surface working against the prosthesis, thus limiting risks for needing a re-intervention $(24,29)$.

A recent comprehensive literature review, which represents the first attempt to summarize up-todate knowledge on TMJ prosthesis in accordance with evidence-based criteria, suggested that total alloplastic temporomandibular joint replacement interventions have showed promising treatment outcomes, and reported improvements are good for both subjective (pain levels, perception of mandibular function, diet consistency, quality of life) and objective (range of movements, jaw motion abnormalities) clinical parameters (28).

At present, a generalization of results is limited by the low number of available studies, which involved only few surgeons and manufacturers, and a better integration of the clinical and research settings should allow improving knowledge on the indications for the intervention, possibly enlarging them. Nonetheless, it must be considered that total joint replacement is a concrete alternative to long-lasting management therapies in many fields of orthopaedic medicine, and its availability should contribute to change the approach to temporomandibular joint disorders, in accordance with literature data on larger joints.
Clinicians managing patients with severe degenerative osteoarthrosis of the TMJ, along with maxillofacial surgeons surgically treating TMJ ankylosis, have to take into consideration the option for an alloplastic replacement of the joint.

This may be particularly important in the field of rheumatology, where a number of systemic conditions (i.e. rheumatoid arthritis, psoriatic arthritis, fibromyalgia) may affect the temporomandibular joint as well and cause severe impairment of jaw function which, in the most severe cases, is difficult to manage with traditional conservative TMD therapies (35-37).

Literature data suggest that, in a follow-up period ranging from one to five years, mean pain reduction was within the $50-67 \%$ range, and increase in mouth opening was about $30 \%$ in cases of severely mutilated and degenerated joints $(25,27,38$ 41). Moreover, a clinical report describing a proposal for a post-surgical protocol in a case of monolateral replacement reported an even more consisting improvement in mouth opening, thus lending support to the hypothesis that a standardization of rehabilitation protocols should help managing the post-surgical phases and allow achieving better improvements than those described so far (42).

In the case of TMJ ankylosis, as that described in this report, improvements in mouth opening are even more marked thanks to the removal of the ankylosis.

As a consequence of these considerations, it appears that a total temporomandibular joint replacement has to be considered as an option to reduce jaw function impairment related to osteoarthrosis and degenerative pathologies affecting the TMJ, along with jaw motion limitations due to TMJ ankylosis.

\section{SUMMARY}

Several conservative treatment approaches to the disorders of the temporomandibular joint (TMJ) have been described in the literature. Nonetheless, in a minority of cases not respondant to reversible conservative therapies a surgical approach to the TMJ is needed. In recent years, a total temporomandibular joint replacement with alloplastic prosthesis have been introduced as a treatment option in the presence of a severely damaged or mutilated joint, mainly resulting from severe joint diseases, as in the case of complex inflammatory-degenerative diseases, or failure of previous surgeries. The present paper described a case report of a bilateral temporomandibular joint replacement intervention in a female patient with severe mouth opening restriction and pain in the TMJ area. Also, a discussion of the potential indications for TMJ replacement has been provided, along with the description of the surgical procedure.

Parole chiave - Articolazione temporo-mandibolare, protesi articolare, chirurgia ATM, disfunzioni ATM, anchilosi ATM.

Key words - Temporomandibular joint, joint prosthesis, TMJ surgery, TMJ disorders, TMJ ankylosis. 


\section{REFERENCES}

1. Okeson JP. Current terminology and diagnostic classification schemes. Oral Surg Oral Med Oral Pathol Oral Radiol Endod 1997; 83: 61-4.

2. Dworkin SF. Perspectives on the interaction of biological, psychological and social factors in TMD. J Am Dent Assoc 1994; 125: 856-63.

3. McNeill C. History and evolution of TMD concepts. Oral Surg Oral Med Oral Pathol Oral Radiol Endod 1997; 83: 51-60.

4. McNeill C. Management of temporomandibular disorders: concepts and controversies. J Prosthet Dent 1997; 77: 510-22.

5. List T, Wahlund K, Wenneberg B, Dworkin SF. TMD in children and adolescents: prevalence of pain, gender differences and perceived treatment need. J Orofac Pain 1999; 13: 9-20.

6. Schiffmann E, Fricton JR, Harley D, Shapiro BL. The prevalence and treatment needs of subjects with temporomandibular disorders. J Am Dent Assoc 1990; 120: 295-304.

7. Manfredini D, Segù M, Bertacci A, Binotti G, Bosco M. Diagnosis of temporomandibular disorders according to RDC/TMD Axis I findings. A multicenter Italian study. Minerva Stomatol 2004; 53: 429-38.

8. Lobbezoo F, Drangsholt M, Peck C, Sato H, Kopp S, Svensson P. Topical Review: New Insights into the Pathology and Diagnosis of Disorders of the Temporomandibular Joint. J Orofac Pain 2004; 18: 181-91.

9. List T, Dworkin SF. Comparing TMD diagnoses and clinical findings at Swedish and US TMD center using Research Diagnostic Criteria for Temporomandibular Disorders. J Orofac Pain 1996; 10: 240-53.

10. Manfredini D, Chiappe G, Bosco M. Research Diagnostic Criteria for Temporomandibular Disorders (RDC/TMD) axis I diagnosis in an italian patients population. J Oral Rehabil 2006; 33: 551-8.

11. Dao TT, Lavigne GJ. Oral splints: the crutches for temporomandibular disorders and bruxism ? Crit Rev Oral Biol Med 1998; 9: 345-61.

12. Raphael K, Marbach JJ. Widespread pain and the effectiveness of oral splints in myofascial face pain. $\mathrm{J}$ Am Dent Assoc 2001; 132: 305-16.

13. Michelotti A, Parisini F, Farella M, Cimino R, Martina R. Fisioterapia muscolare in pazienti con disordini temporomandibolari. Studio clinico controllato. Minerva Stomatol 2000; 49: 541-8.

14. De Laat A, Stappaers K, Papy S. Counseling and physical therapy as treatment for myofascial pain of the masticatory system. J Orofac Pain 2003; 17: 42-9.

15. Dionne RA. Pharmacologic treatments for temporomandibular disorders. Oral Surg Oral Med Oral Pathol Oral Radiol Endod 1997; 83: 134-42.

16. Manfredini D, Romagnoli M, Cantini E, Bosco M. Efficacy of tizanidine hydrochloride in the treatment of myofascial face pain. Minerva Med 2004; 95: 165-71.

17. Dionne RA. Pharmacologic treatment of acute and chronic orofacial pain. Oral Maxillofac Surg Clin North Am 2000; 12: 309-20.
18. Plesh O, Curtis D, Levine J, Mccall WD. Amitriptyline treatment of chronic pain in patients with temporomandibular disorders. J Oral Rehabil 2000; 27: 834-41.

19. Dimitroulis G. The role of surgery in the management of disorders of the temporomandibular joint: a critical review of the literature. Part 1. Int J Oral Maxillofac Surg 2005; 34: 107-113.

20. Guarda-Nardini L, Masiero S, Marioni G. Conservative treatment of temporomandibular joint osteoarthrosis: intra-articular injection of hyaluronic acid. J Oral Rehabil 2005; 32: 729-34.

21. Guarda-Nardini L, Tito R, Staffieri A, Beltrame A. Treatment of patients with arthrosis of the temporomandibular joint by infiltration of hyaluronic acid: a preliminary study. Eur Arch Otorhinolaryngol 2002; 259: 279-84.

22. Nitzan DW, Dolwick MF. Artrhroscopyc lavage and lysis of the TMJ: a change in perspective. J Oral Maxillofac Surg 1990; 48:798-801.

23. Guarda-Nardini L, Stifano M, Brombin C, Salmaso L, Manfredini D. A one year case series of arthrocentesis with hyaluronic acid injections for temporomandibular joint osteoarthritis. Oral Surg Oral Med Oral Pathol Oral Radiol Endod 2007, in press.

24. Mercuri LG. Considering total temporomandibular joint replacement. Cranio 1999; 17: 44-8.

25. Mercuri LG, Giobbie-Hurder A. Long-term outcomes after total alloplastic temporomandibular joint reconstruction following exposure to failed materials. J Oral Maxillofac Surg 2004; 62: 1088-96.

26. Mercuri LG. Alloplastic temporomandibular joint reconstruction. Oral Surg Oral Med Oral Pathol Oral Radiol Endod 1998; 85: 631-7.

27. Wolford LM, Dingwerth DJ, Talwar RM, Pitta MC. Comparison of 2 temporomandibular joint total joint prosthesis systems. J Oral Maxillofac Surg 2003; 61: 685-90.

28. Guarda Nardini L, Manfredini D, Ferronato G. Temporomandibular joint total replacement prosthesis: current knowledge and considerations for the future. Int $\mathrm{J}$ Oral Maxillofac Surg 2007, in press.

29. Quinn PD. Lorenz Prosthesis. Oral Maxillofac Surg Clin North Am 2000; 12: 93-104.

30. Manfredini D, Bucci MB, Guarda Nardini L, Ferronato $\mathrm{G}$. Temporomandibular joint bilateral post-traumatic ankylosis: a report of a case treated with interpositional arthroplasty. Minerva Stomatol 2007, in press.

31. Manganello-Souza LC, Mariani PB. Temporomandibular joint ankylosis: report of 14 cases. Int $\mathrm{J}$ Oral Maxillofac Surg 2003; 32: 24-9.

32. Su-Gwan K. Treatment of temporomandibular joint ankylosis with temporalis muscle and fascia flap. Int $\mathrm{J}$ Oral Maxillofac Surg 2001; 30: 189-93.

33. Erol B, Tanrikulu R, Gorgun B. A clinical study on ankylosis of the temporomandibular joint. J Craniomaxillofac Surg 2006; 34: 100-6.

34. Valentini V, Vetrano S, Agrillo A, Torrino A, Fabiani F, Iannetti G. Surgical treatment of TMJ ankylosis: our experience (60 cases). J Craniofac Surg 2002; 13: 5967. 
35. Salvetti G, Manfredini D, Bazzichi L, Bosco M. Clinical features of the stomatognathic involvement in fibromyalgia syndrome: a comparison with temporomandibular disorders patients. Cranio 2007; 25: 127-33.

36. Manfredini D, Salvetti G. Orofacial involvement and temporomandibular disorders symptoms in fibromyalgia. In: Pederson JA (ed). New research on fibromyalgia. Nova Science Publishers, 2006; 99-110.

37. Koh ET, Yap AU, Koh CK, Chee TS, Chan SP, Boudville IC. Temporomandibular disorders in rheumatoid arthritis. J Rheumatol 1999; 26: 1918-22.

38. Mercuri LG. Subjective and objective outcomes in patients reconstructed with a custom-fitted alloplastic temporomandibular joint prosthesis. J Oral Maxillofac Surg 1999; 57: 1427-30.
39. Speculand B, Hensher R, Powell D. Total prosthetic replacement of the TMJ: experience with two systems 1988-1997. Br J Oral Maxillofac Surg 2002; 38: 36069.

40. Mercuri LG, Sanders B, Giobbie-Hurder A. Long-term follow-up of the CAD/CAM patient fitted total temporomandibular joint reconstruction system. J Oral Maxillofac Surg 2002; 60: 1440-8.

41. Christensen RW, Walker CR, Dollar JV. New hope for Treacher-Collins syndrome: a surgical case report. Surg Technol Int 2005; 14: 319-27.

42. Guarda Nardini L, Manfredini D, Ferronato G. Total temporomandibular joint replacement: a clinical case with a proposal for post-surgical rehabilitation. J Craniomaxillofac Surg (sumbitted). 